IN BRIEFS

\section{CONNECTIVE TISSUE DISEASES}

Low-dose intravenous therapy with iloprost ( $0.5 \mathrm{ng} / \mathrm{kg}$ body weight per $\mathrm{min}$ ) has been shown to be as effective as high-dose intravenous therapy (up to $2 \mathrm{ng} / \mathrm{kg}$ body weight per min) for the treatment of patients with systemic sclerosis. In a randomized, open-label study of 50 patients, $78 \%$ reported long-lasting benefits. Both regimens reduced skin ulcers by $70 \%$ and reduced the frequency and duration of Raynaud's phenomenon by $40 \%$ and $30 \%$, respectively.

Original article Kawald A et al. (2008) Low versus high-dose iloprost therapy over 21 days in patients with secondary Raynaud's phenomenon and systemic sclerosis: a randomized, open, single-center study. J Rheumatol 35: 1830-1837

Enteric-coated mycophenolate sodium produces fewer adverse effects than mycophenolate mofetil, and could be a safe and effective alternative to extended courses of intravenous cyclophosphamide in the treatment of cyclophosphamide-resistant proliferative lupus nephritis. In a recent study, 31 patients treated for 6 months with entericcoated mycophenolate showed response rates similar to those of historical controls treated with intravenous cyclophosphamide, with fewer adverse effects.

Original article Traitanon O et al. (2008) Efficacy of enteric-coated mycophenolate sodium in patients with resistant-type lupus nephritis: a prospective study. Lupus 17: $744-751$

\section{VASCULITIS SYNDROMES}

A study comparing the diagnostic performance of high-resolution MRI and color-coded duplex sonography in 59 patients with suspected giant cell (temporal) arteritis did not find significant differences between their sensitivity, specificity and positive and negative predictive values. Both of these noninvasive techniques could be valuable in the diagnosis of giant cell arteritis; the decision of which technique to use could depend on the clinical setting.

Original article Bley TA et al. (2008) Comparison of duplex sonography and high-resolution magnetic resonance imaging in the diagnosis of giant cell (temporal) arteritis. Arthritis Rheum 58: 2574-2578

\section{RHEUMATOID ARTHRITIS}

In an effort to identify biomarkers predictive of therapeutic response to biologics in rheumatoid arthritis, a proteomic study examined the plasma profiles of 60 patients with differential responses to infliximab treatment. Analysis revealed six plasma biomarkers that were differentially expressed in responders and nonresponders; several biomarkers in combination predicted patient response with high sensitivity and specificity (both $>97 \%$ ). Apolipoprotein A-I was associated with response, whereas platelet factor 4 was associated with nonresponse.

Original article Trocmé C et al. (2008) Apolipoprotein A-I and platelet factor 4 are biomarkers for infliximab response in rheumatoid arthritis. Ann Rheum Dis [doi: 10.1136/ ard.2008.093153]

In patients with concurrent rheumatoid arthritis and chronic hepatitis $C$ infection, treatment with anti-tumor necrosis factor (TNF) therapy is controversial, as it could exacerbate hepatitis. The results of a recent study, however, support the use of anti-TNF agents in these patients, provided transaminase levels and viremia are closely monitored. Significant improvements in serological and clinical symptoms were observed after 3 months of anti-TNF treatment; persistently abnormal levels of transaminases (unrelated to viremia) caused discontinuation of treatment in 1 of the 28 patients in the study.

Original article Ferri C et al. (2008) Safety of anti-tumor necrosis factor-alpha therapy in patients with rheumatoid arthritis and chronic hepatitis $\mathrm{C}$ virus infection. J Rheumatol [First Release Aug 12008 ]

\section{METABOLIC BONE DISEASES}

The rate of osteoporosis treatment prescribed for postmenopausal women with acute wrist fracture is increased by a multifacted intervention consisting of a reminder and treatment guidelines sent to physicians and an educational package sent to patients. In a cluster randomized trial of 270 patients, a higher proportion of women were prescribed osteoporosis medication and underwent a bone mineral density test in the intervention group than in the usual care group ( $28 \%$ vs $10 \%$ and $53.3 \%$ vs $26 \%$, respectively).

Original article Cranney A et al. (2008) A multifaceted intervention to improve treatment of osteoporosis in postmenopausal women with wrist fractures: a cluster randomized trial. Osteoporos Int [doi:10.1007/s00198-0080669-0] 